\title{
Pedigree Analysis and Audiological Investigations of Otosclerosis: An Extended Family Based Study
}

\author{
Santhanam Rekha ${ }^{1}$, Ravi Ramalingam² ${ }^{2}$ and Madasamy Parani ${ }^{1}$ \\ ${ }^{1}$ Genomics Laboratory, Department of Genetic Engineering, SRM University, Kattankulathur, Kancheepuram, India \\ ${ }^{2}$ KKR ENT Hospital and Research Institute, Chennai, India
}

\section{Received March 14, 2018 \\ Revised April 10,2018 \\ Accepted April 12, 2018}

\section{Address for correspondence \\ Madasamy Parani, MSc, $\mathrm{PhD}$ \\ Genomics Laboratory, \\ Department of Genetic Engineering, \\ SRM University, Kattankulathur, \\ Tamilnadu-603203, India \\ Tel +914427417817 \\ Fax +914427453903 \\ E-mail parani.m@ktr.srmuniv.ac.in}

Background and Objectives: To analyse the audiometric profile and the pedigree of a large family with otosclerosis to understand the inheritance pattern and its implication in clinical management of the disease. Subjects and Methods: Pedigree analysis was performed on the basis of family history and audiometric tests. Pure tone audiometry, tympanometry, and acoustic reflexes were evaluated for the family members. Audiometric analysis was also carried out for the individuals who have already underwent corrective surgery at the time of study. Results: Out of 112 family members, 17 were affected individuals, and 11 of them were surgically confirmed. Hearing loss $(\mathrm{HL})$ started unilaterally and progressed to bilateral form. Otosclerosis was presented in early 20's in the first and second generations but it was delayed to mid-late 30's in the fourth generation. An affected female was diagnosed with otosclerosis during her pregnancy. Though the disease was familial, a mother of four affected offspring in this family did not develop otosclerosis until she died at the age of 84 . Conclusions: The five-generation family, which was analysed in the present study, exhibited autosomal dominant inheritance of otosclerosis with reduced penetrance. Bilateral $\mathrm{HL}$ and pregnancy-aggravated otosclerosis were observed in this family. It was found for the first time that the age of onset of the disease delayed in the successive generations. The current study indicated the importance of detailed pedigree analysis for better clinical management of otosclerosis.

J Audiol Otol 2018;22(4):223-228

KEY WORDS: Familial otosclerosis · Conductive hearing loss · Pedigree analysis · Autosomal dominant.

\section{Introduction}

Otosclerosis is the most common cause of adult-onset hearing loss (HL), and typically occurs in the 2nd to 4th decade of life. It is caused by abnormal bone homeostasis in the otic capsule, which leads to fixation of the stapes footplate in the oval window. This fixation disturbs transmission of sound waves through the middle ear ossicles to the cochlea, which results in conductive hearing impairment and progressively affects sensorineural components in a patients' later years. The disease is bilateral in $70-80 \%$ cases [1].

This is an Open Access article distributed under the terms of the Creative Commons Attribution Non-Commercial License (https://creativecommons.org/licenses/by-nc/4.0/) which permits unrestricted non-commercial use, distribution, and reproduction in any medium, provided the original work is properly cited.
The prevalence of otosclerosis was estimated to be $0.2-$ $1 \%$ in Caucasians but rare among Africans, Asians, and Amerindians. However, a higher incidence (to an extent of $17 \%$ ) was reported in the Todas tribal population from South India. The higher incidence is attributed to endogamous marriages within the tribal population [2,3]. Pregnancy aggravates the $\mathrm{HL}$ in females, and hence, prevalence of otosclerosis is estimated to be twice as frequent in females as in males [4,5]. A familial history of otosclerosis is commonly reported in 50\% of the patients [5].

For clinical diagnosis, non-invasive audiological examinations such as pure tone audiometry (PTA), tympanometry, and acoustic reflex measurements are traditionally performed. Characteristic diagnostic features are normal tympanic membranes, conductive HL in PTA, and type 'As' tympanometric graph. PTA is analysed based on the air-bone gap 
that establishes the presence of conductive components involved in HL. Although Carhart's notch (elevated bone conduction threshold at 2,000 Hz) was reported as the hallmark audiological sign of otosclerosis [6], it was later found to be not present in all the otosclerosis patients [7-9].

In this study, we describe a large, five-generation South Indian family with otosclerosis. This family exhibited several characteristics: 1) progressive bilateral HL; 2) pregnancyaggravated HL; and 3) reduced penetrance of the disease.

\section{Subjects and Methods}

\section{Identification of potential family}

In this study, we identified a five-generation family with otosclerosis from Kancheepuram District, Tamil Nadu, India. The family was recruited as per the Institutional Ethical Board (Ethical letter No: 796/IEC/2015). After getting informed consent, medical history of the individuals was recorded with special emphasis on age of disease onset and symmetry of the hearing impairment.

\section{Clinical examination}

Audiological tests were performed for the individuals who were above 35 years. PTA was performed for both air and bone conduction in both ears. Threshold values were recorded at $0.125,0.25,0.5,1,2,3,4,6$, and $8 \mathrm{kHz}$ for both ears. PTA, tympanometry, immittance audiometry, acoustic reflexes, and otoacoustic emission tests were evaluated under expert supervision. The individuals categorised as affected if they show minimal criteria of otosclerosis having normal tympanic membrane, conductive or mixed HL together with absence of stapedial reflexes in the audiometric analysis. The spouses in the family were not included in the study.

\section{Construction of pedigree}

The family history was carefully collected and a five-generation pedigree was constructed. The individuals who underwent corrective surgery for otosclerosis were confirmed as affected and other individuals in the family who were consenting to take part in the study were examined for audiometric profile. Information on the deceased individuals was obtained from the family members. In the pedigree chart, open circle and square represent female and male, respectively. The shaded symbols represent affected individuals. Pedigree chart was constructed for the family using Progeny CLINICAL version 9 (Progeny Software LLC, Delray Beach, FL, USA).

\section{Results}

This study was initiated from a 62 year old male (III:8) who was diagnosed with otosclerosis at the age of 35 in the left ear, and later progressed to bilateral HL in his 50's. At the age of 41 , he had showed severe mixed HL and moderate conductive HL in left and right ear respectively. The lack of knowledge on the disease and awareness on the surgery led him live with the inability for certain years. Later, when the hearing is deteriorated in both ears, he had undergone stapedotomy at the age of 56 . His nine years postoperative audiogram showed sensorineural HL in left ear and severe mixed HL in right ear (Fig. 1). The family medical history was collected from the family members. The five-generation family consisted of a total of 112 members (56 females and 56 males), 78 were descendants of the ancestral parents. Among them, eleven individuals ( 7 males and 4 females) experienced HL between 17 and 39 years of age, and had undergone stapedotomy for correcting HL (Table 1). Stapedotomy also excluded other middle ear pathologies thus confirming otosclerosis in these individuals.

Three members in the second generation (II:1, II:2, and II:5) were presented with unilateral HL in their early 20's. Right ear was affected in II:1, II:5, whereas left ear was affected in II:2. All of them had undergone stapedotomy in the affected ears. The audiograms of II:1 and II:5 aged over 80 years showed profound HL in the unoperated ears (Fig. 1). Four members in the third generation (III:3, III:7, III:9, and III:16) were also presented with unilateral HL in their early 20's. All of them have experienced HL in the left ear, and hearing was restored after stapedotomy. Forty years after surgery, III:3 showed severe mixed HL and III:16 showed mild conductive HL in the unoperated ears respectively (Fig. 1).

One of the affected females in the third generation (III:11) was diagnosed with otosclerosis during her pregnancy at the age of 25. Conductive HL was experienced in the left ear during the second trimester of G1P0. One year post-partum G1P1, she had mixed HL in the left ear and stapedotomy was performed to restore hearing. Hearing was normal in right ear at that time, however, HL progressed to the right ear also in her late 50's (Fig. 1) and she underwent surgery in that ear in order to reinstate hearing.

Two individuals (IV:11 and IV:12) in the fourth generation were presented with the symptoms of HL at the age of 35 and 39, respectively. Both of them had undergone surgery; IV:11 in left ear and IV:12 in right ear (Fig. 1).

In addition, thirteen descendants of the ancestral parents were evaluated for hearing threshold. As shown in Fig. 1, the audiometric profiles of four individuals (III:5, III:6, III:17, 


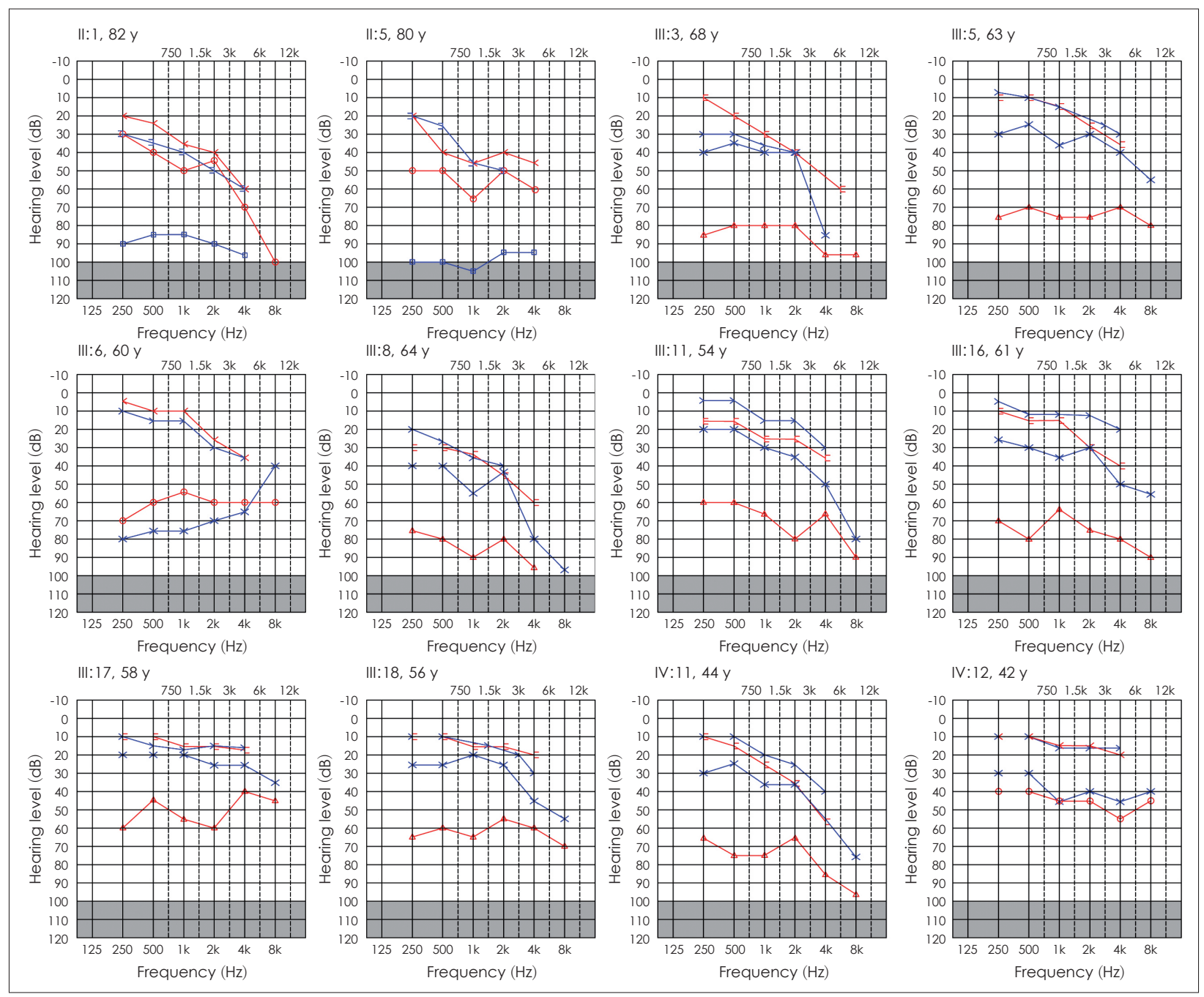

Fig. 1. Pure tone audiograms of affected individuals in the family. The individuals were labelled with the ID and their age at the time of the study. Air conduction without masking $(\bigcirc$ and $\times$ ), air conduction with masking ( $\triangle$ and $\square$ ), bone conduction without masking ( $<$ and $>$ ), and bone conduction with masking ( ] and [ ) are marked in red and blue lines for right and left ear, respectively.

and III:18) indicated different degree of hearing impairment. The individuals III:5, III:17, and III:18 showed mild conductive HL in right ear, and III:6 showed moderate mixed HL in left ear and severe mixed HL in right ear. The other nine individuals showed normal hearing threshold at the time of testing.

The pedigree was constructed for the five-generation family with 112 members of which 17 were affected with otosclerosis. The affected individuals included 11 males and 6 females. As shown in the pedigree (Fig. 2), the affected female in the first generation had one affected male, three affected females, and one unaffected female offspring. The affected male had consanguineous marriage with an unaffected female, and did not have any affected offspring. The remaining two affected females had three affected offspring each in the third generation. Interestingly, the unaffected female had four affected offspring. One of the affected offspring (III:7) had two affected offspring in the fourth generation also (IV:11 and IV:12). Remaining individuals in the fourth generation and all the individuals in the fifth generation have not yet attained the age to show the symptoms of otosclerosis.

\section{Discussion}

Otosclerosis is an autosomal dominant disease, however, in some cases, the defective gene may not lead to the disease due to reduced penetrance $[10,11]$. Genome-wide linkage studies demonstrated that otosclerosis is heterogenetic nature. The first locus for otosclerosis (OTSC1) was located on chromosome $15 q$ in a South Indian population [12]. Subsequently, OTSC2, OTSC3, OTSC4, OTSC5, OTSC7, OTSC8, and OTSC10 located on chromosome 7q, 6p, 16q, 3q, 6q, 9q, 
Table 1. Age at the time of study, age at which otosclerosis was diagnosed, age at which corrective surgery (stapedotomy) was done, and the postoperative audiometric profiles of the 17 affected individuals of the family

\begin{tabular}{|c|c|c|c|c|c|c|c|c|c|c|}
\hline \multirow[b]{2}{*}{ No } & \multirow[b]{2}{*}{ Code } & \multirow[b]{2}{*}{ Age } & \multirow{2}{*}{$\begin{array}{c}\text { Age } \\
\text { of diagnosis/ } \\
\text { surgery }\end{array}$} & \multicolumn{2}{|c|}{ Pure tone audiometry } & \multicolumn{2}{|c|}{ Tympanometry } & \multirow{2}{*}{$\begin{array}{l}\text { Acoustic } \\
\text { reflex } \\
\text { left/right }\end{array}$} & \multirow{2}{*}{$\frac{\text { OAE }}{\text { Left/right }}$} & \multirow[b]{2}{*}{ Surgery } \\
\hline & & & & Left & Right & Left & Right & & & \\
\hline 1 & I:1 & Deceased & NA & NA & NA & NA & NA & NA & NA & NA \\
\hline 2 & $\|: 1$ & 82 & $19 / 22$ & Profound $\mathrm{HL}$ & $\begin{array}{l}\text { Moderate to } \\
\text { mixed } \mathrm{HL}\end{array}$ & $A$ & A & $-/-$ & $-/-$ & Right \\
\hline 3 & $\|: 2$ & Deceased & $-/ 20$ & NA & NA & NA & NA & NA & NA & Left \\
\hline 4 & $11: 3$ & Deceased & NA & NA & NA & NA & NA & NA & NA & NA \\
\hline 5 & $\|: 5$ & 80 & $20 / 21$ & $\begin{array}{l}\text { Moderate } \\
\text { SN HL }\end{array}$ & $\begin{array}{l}\text { Profound } \\
\text { mixed HL }\end{array}$ & As & C & $-/-$ & $-/-$ & Right \\
\hline 6 & $111: 3$ & 68 & $22 / 23$ & $\begin{array}{l}\text { Moderate } \\
\text { SN HL }\end{array}$ & $\begin{array}{l}\text { Severe mixed } \\
\mathrm{HL}\end{array}$ & A & As & $-/-$ & $-/-$ & Left \\
\hline 7 & III:5 & 63 & $63 /-$ & Mild mixed HL & $\begin{array}{l}\text { Severe mixed } \\
\mathrm{HL}\end{array}$ & $A$ & A & $+/-$ & $-/-$ & - \\
\hline 8 & III:6 & 60 & $60 /-$ & $\begin{array}{l}\text { Moderate } \\
\text { mixed HL }\end{array}$ & $\begin{array}{l}\text { Severe mixed } \\
\mathrm{HL}\end{array}$ & $A$ & A & $-/-$ & $-/-$ & - \\
\hline 9 & III:7 & 62 & $25 / 58$ & NA & NA & A & A & NA & NA & Left \\
\hline 10 & III:8 & 64 & $34 / 56$ & $\begin{array}{l}\text { Moderate to } \\
\text { Severe SN HL }\end{array}$ & $\begin{array}{l}\text { Severe mixed } \\
\mathrm{HL}\end{array}$ & A & Ad & $-/-$ & $-/-$ & Left \\
\hline 11 & $111: 9$ & 61 & $34 / 34$ & NA & NA & NA & NA & NA & NA & Left \\
\hline 12 & III:11 & 54 & $\begin{array}{c}25 /[27(\mathrm{~L}) \& \\
52(\mathrm{R})]\end{array}$ & $\begin{array}{l}\text { Mild } \\
\text { conductive HL }\end{array}$ & $\begin{array}{l}\text { Mild } \\
\text { conductive } \mathrm{HL}\end{array}$ & As & As & NA & NA & Both ears \\
\hline 13 & III:16 & 61 & $33 / 35$ & $\begin{array}{l}\text { Mild } \\
\text { conductive HL }\end{array}$ & $\begin{array}{l}\text { Severe } \\
\text { mixed } \mathrm{HL}\end{array}$ & $A$ & A & $-/-$ & $-/-$ & Left \\
\hline 14 & III:17 & 58 & $58 /-$ & Normal & $\begin{array}{l}\text { Moderate } \\
\text { conductive HL }\end{array}$ & B & A & $+/-$ & $+/-$ & - \\
\hline 15 & III:18 & 56 & $56 /-$ & Normal & $\begin{array}{l}\text { Moderately } \\
\text { severe con- } \\
\text { ductive HL }\end{array}$ & A & A & $+/-$ & $+/-$ & - \\
\hline 16 & $I V: 11$ & 44 & $34 / 34$ & Mild SN HL & $\begin{array}{l}\text { Severe mixed } \\
\mathrm{HL}\end{array}$ & A & A & $-/-$ & $-/-$ & Left \\
\hline 17 & $\mathrm{IV}: 12$ & 42 & $39 / 39$ & $\begin{array}{l}\text { Mild } \\
\text { conductive HL }\end{array}$ & $\begin{array}{l}\text { Mild } \\
\text { conductive } \mathrm{HL}\end{array}$ & As & As & NA & NA & Right \\
\hline
\end{tabular}

$\mathrm{HL}$ : hearing loss, SN: Sensorineural, +: present, -: absent, NA: not available, OAE: otoacoustic emission tests

and $1 \mathrm{q}$ were reported from other populations. In addition, OTSC6 and OTSC9 were identified, but their chromosomal locations are not known [13]. Despite that 10 loci were reported, candidate genes for otosclerosis are yet to be identified. Studies on the association between otosclerosis and the genes involved in bone metabolism pathway such as transforming growth factor $\beta$ (TGF $\beta$ ), reelin (RELN), noggin (NOG), collagen type alpha 1 and 2 (COL1A1 and COL1A2) remain inconclusive [14].

Otosclerosis causes a significant disability in both personal and professional lives at a young age. The affected individuals seek medical advice only when the hearing threshold is reduced to a greater extent. Occurrence of the disease varies from individual to individual with age, gender, ethnicity, and lifestyle. Normally audiometry is used for clinical diagnosis of otosclerosis, however, being a familial disorder, a thorough family history should be collected and pedigree must be constructed with ascertainment of cases [15]. The family pedigree greatly helps the clinician in early diagnosis and better disease management for the individuals with suggestive otosclerotic audiometric profile.

In the current study, a large five-generation family was investigated for clinical and genetic aspects. In this family, bilateral HL predominantly started in the left ear and progressed to the right ear. Generally, otosclerosis occurs more often in females than males due to pregnancy-induced aggravation of the disease. However, in the third generation of the family analysed in this study, more number of males were affected than females because of skewed gender ratio in this generation. While the affected individuals were in their early 


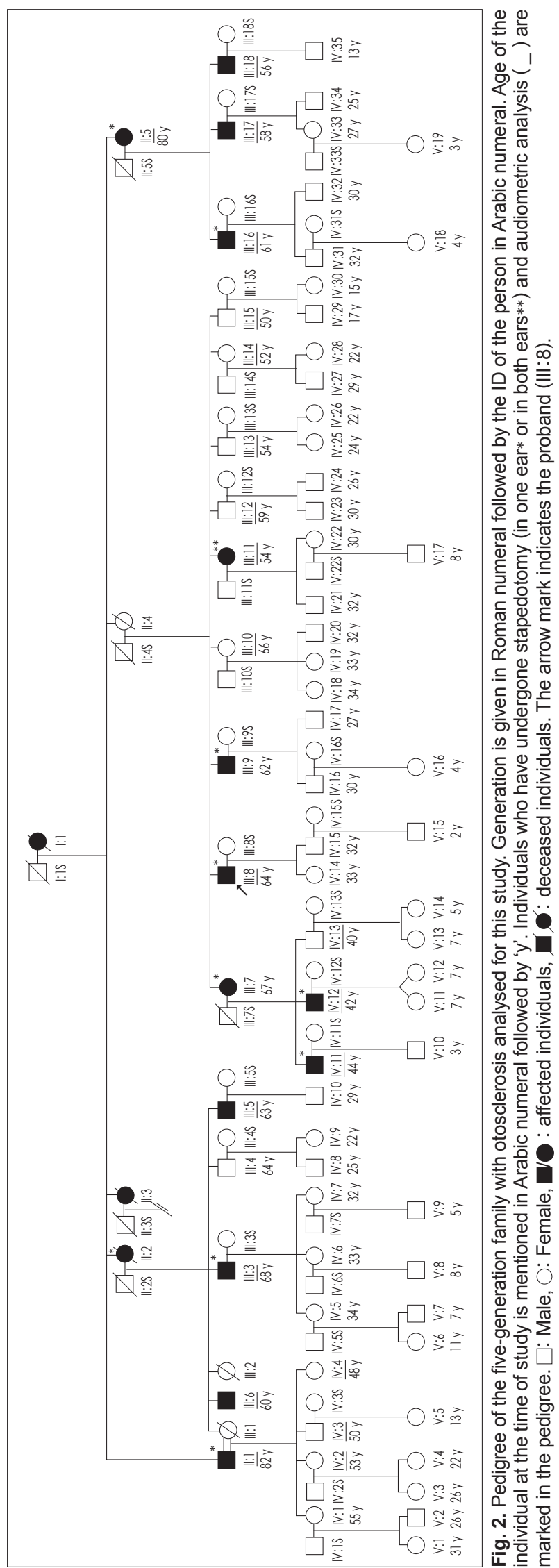

20 's in the first and second generations, they were in midlate 30's in the fourth generation. This indicated that the onset of the disease is delayed in the successive generations. Whether it is a common phenomenon in otosclerosis requires a detailed study in a larger cohort of familial cases. It is worthwhile to mention that a retrospective study reported that the onset of otosclerosis may be delayed due to vaccination against measles, use of low-dose contraception drugs, and improved healthcare [16].

In one branch of this family, a mother of four affected offspring did not develop otosclerosis until she died at the age of 84. Otosclerosis being an autosomal dominant disease, this can be explained only by reduced penetrance of the disease in this individual. Penetrance level for this disease was reported to range between 50 and 90 percent $[4,10]$. In another branch of this family, a consanguineously married couple did not have any affected offspring, which seems to be rare incidence. However, the benefit of low penetrance of the diseases in this branch cannot be ruled out.

Patients who have otosclerosis with family history should be informed about the dominant heritable nature of the disease, and its normal age of onset to explain that younger members of the family may get the disease. Since genetic tests for otosclerosis are not available, the importance of avoiding consanguineous marriage should be emphasised.

Pathophysiology of the otosclerosis is poorly understood and diagnosis of otosclerosis is challenging to exclude the other middle ear pathologies. Documenting the family history and analysis of pedigree will be useful in early diagnosis and management of the disease. The findings in this family are consistent with the reported observation of bilateral HL, influence of pregnancy on disease development, and autosomal dominant inheritance pattern with reduced penetrance. The conclusions from this study may be limited to some extent due to the lack of CT scan data for the affected individuals. Another limitation is that more affected families need to be studied to conclusively establish pregnancy-aggravated onset of the diseases, and delayed onset of the disease in the successive generations.

\section{Acknowledgments}

This study was financially supported by SRM-DBT Partnership Platform for Contemporary Research Services and Skill Development in Advanced Life Sciences Technologies (Order No. BT/ PR12987/INF/22/205/2015). We also thank the family members who participated in the study.

\section{Conflicts of interest}

The authors have no financial conflicts of interest. 


\section{REFERENCES}

1) Rudic M, Keogh I, Wagner R, Wilkinson E, Kiros N, Ferrary E, et al. The pathophysiology of otosclerosis: review of current research. Hear Res 2015;330(Pt A):51-6.

2) Kapur YP, Patt AJ. Otosclerosis in South India. Acta Otolaryngol 1966;61:353-60.

3) Kameswaran S, Kumar PV, Jeyapaul JI, Manoharan S. Audiological and haematological studies on the Todas of Nilgiris. J Laryngol Otol 1976;90:325-33.

4) Thys M, Van Camp G. Genetics of otosclerosis. Otol Neurotol 2009; 30:1021-32.

5) Hain TC, Micco A. Otosclerosis [cited 2017 September 11]. Available from: http://american-hearing.org/disorders/otosclerosis/.

6) Carhart R. Clinical application of bone conduction audiometry. Arch Otolaryngol 1950;51:798-808.

7) Kashio A, Ito K, Kakigi A, Karino S, Iwasaki S, Sakamoto T, et al. Carhart notch $2-\mathrm{kHz}$ bone conduction threshold dip: a nondefinitive predictor of stapes fixation in conductive hearing loss with normal tympanic membrane. Arch Otolaryngol Head Neck Surg 2011;137: 236-40.

8) Lee HM, Kim SH, Jung JH, Oh SJ, Kong SK, Lee IW. Clinical and audiological characteristics of $1000 \mathrm{~Hz}$ audiometric notch patients.
Am J Otolaryngol 2017;38:521-5

9) Perez R, de Almeida J, Nedzelski JM, Chen JM. Variations in the "Carhart notch" and overclosure after laser-assisted stapedotomy in otosclerosis. Otol Neurotol 2009;30:1033-6.

10) Moumoulidis I, Axon P, Baguley D, Reid E. A review on the genetics of otosclerosis. Clin Otolaryngol 2007;32:239-47.

11) Ealy M, Smith RJ. The genetics of otosclerosis. Hear Res 2010;266: 70-4.

12) Tomek MS, Brown MR, Mani SR, Ramesh A, Srisailapathy CR, Coucke $\mathrm{P}$, et al. Localization of a gene for otosclerosis to chromosome 15q25-q26. Hum Mol Genet 1998;7:285-90.

13) Hereditary Hearing Loss-Hereditary Hearing loss Homepage. Clinical otosclerosis [cited 2017 Sept 11]. Available from: http://hereditaryhearingloss.org/main.aspx?c=.HHH\&n=86521.

14) Schrauwen I, Van Camp G. The etiology of otosclerosis: a combination of genes and environment. Laryngoscope 2010;120:1195-202.

15) Saeed SR, Briggs M, Lobo C, Al-Zoubi F, Ramsden RT, Read AP. The genetics of otosclerosis: pedigree studies and linkage analysis. Adv Otorhinolaryngol 2007;65:75-85.

16) Niedermeyer HP, Häusler R, Schwub D, Neuner NT, Busch R, Arnold W. Evidence of increased average age of patients with otosclerosis. Adv Otorhinolaryngol 2007;65:17-24. 